\title{
Risk-reducing Salpingo-Oophorectomy in Women at Higher Risk of Ovarian and Breast Cancer: A Single Institution Prospective Series
}

\author{
ENZO RICCIARDI*, FEDERICA TOMAO*, GIOVANNI ALETTI, LUCA BAZZURINI, \\ LUCA BOCCIOLONE, SARA BOVERI, FABIO LANDONI, MARIA TERESA LAPRESA, \\ MATTEO MARUCCIO, GABRIELLA PARMA, FEDRO PECCATORI, MARIA CRISTINA PETRELLA, \\ VANNA ZANAGNOLO, NICOLETTA COLOMBO and ANGELO MAGGIONI \\ Division of Gynecology, European Institute of Oncology, Milan, Italy
}

\begin{abstract}
Background/Aim: Occult cancers' reported rates vary from $2-12 \%$ and serous tubal intraepithelial carcinomas (STICs) have been identified in 3-12\% of the prophylactically removed tubes of women carrying a BRCA mutation. The aim of this study was to evaluate the incidence of tubal minor epithelial atypia (STIL), STIC, and occult invasive cancer and to evaluate the cancer-specific mortality in a prospective series of women at higher risk of ovarian and breast cancer undergoing risk-reducing salpingo-oophorectomy (RRSO) $n$ a tertiary cancer center. Patients and Methods: A series of RRSO specimens (including endometrial biopsy) from women carrying a BRCA mutation, BRCA-unknown and BRCA-negative were collected between January 1998 and April 2016 at the Division of Gynecology at the European Institute of Oncology. Inclusion criteria were: asymptomatic women who had a negative gynecologic screening within 3 months prior to RRSO. Exclusion criteria were: women with ovarian/tubal cancer prior to RRSO. Results: A total of 411 women underwent RRSO. Median age at RRSO was 47.0 years (range $=32-70$ years); $75.2 \%$ had a history of breast cancer. Fifteen women were diagnosed with an occult cancer (7 STIC, 4 invasive cancers, 2 breast cancers metastatic to the adnexa, 2 endometrial cancer) (3.6\%). Sixteen showed a STIL (3.9\%). When excluding cases with preoperative positive markers, the occult invasive cancer
\end{abstract}

\footnotetext{
*These Authors contributed equally to this study.

Correspondence to: Enzo Ricciardi, Division of Gynecology, European Institute of Oncology, Milan, Italy. Tel: +39 02574891, e-mail: enzo.ricciardi@ieo.it
}

Key Words: Risk-reducing salpingo-oophorectomy, BRCA genes, breast cancer, ovarian cancer, STIC. rate drops to $1.5 \%$. Conclusion: Our study, covering an 18year period, shows a substantial low risk of occult cancer among a high-risk population of women undergoing RRSO. Our data still support the indication for RRSO in higherrisk patients. An endometrial biopsy should also be routinely obtained as it raises the chances of detecting occult endometrial cancers that may be otherwise missed.

Ovarian cancer (OC) is the fifth leading cause of oncologyrelated death in women (1). With a family history of cancer an increased risk of this disease is observed: the lifetime risk for women with one first-degree relative affected by ovarian cancer is $3.5-7 \%$ and it increases to $15 \%$ when two firstdegree relatives are affected (2).

Women who are at a higher risk of developing cancer may undergo different risk-reducing strategies, which include intensive screening, chemoprevention and surgical prophylaxis. The diffusion of more intensive screening programs for hereditary breast cancer (BC) led to early detection of this tumor.

On the contrary, OC is usually asymptomatic for long time and prevention from this tumor is still not available. Therefore, the recommendation for women carrying a BRCA1/2 mutation is salpingo-oophorectomy (RRSO) that lowers the risk for ovarian cancer up to $>95 \%$ and the risk for BC up to $50 \%$ (3). A cohort study by Domchek et al. proved a breast cancer specific, ovarian cancer specific and OS benefit from RRSO (4). The residual risk for peritoneal cancer after PBSO accumulates to $3.5 \%$ after 20 years of follow-up (5).

Occult cancers have been reported in prophylactically removed ovaries and fallopian tubes in women carrying a $B R C A$ mutation. Reported rates vary considerably from 2$12 \%$ and seem to be influenced by patients' age at RRSO, symptoms, gynecologic screening prior to RRSO, the completeness of prophylactic surgery and the accuracy of histopathological examination (6-16). 


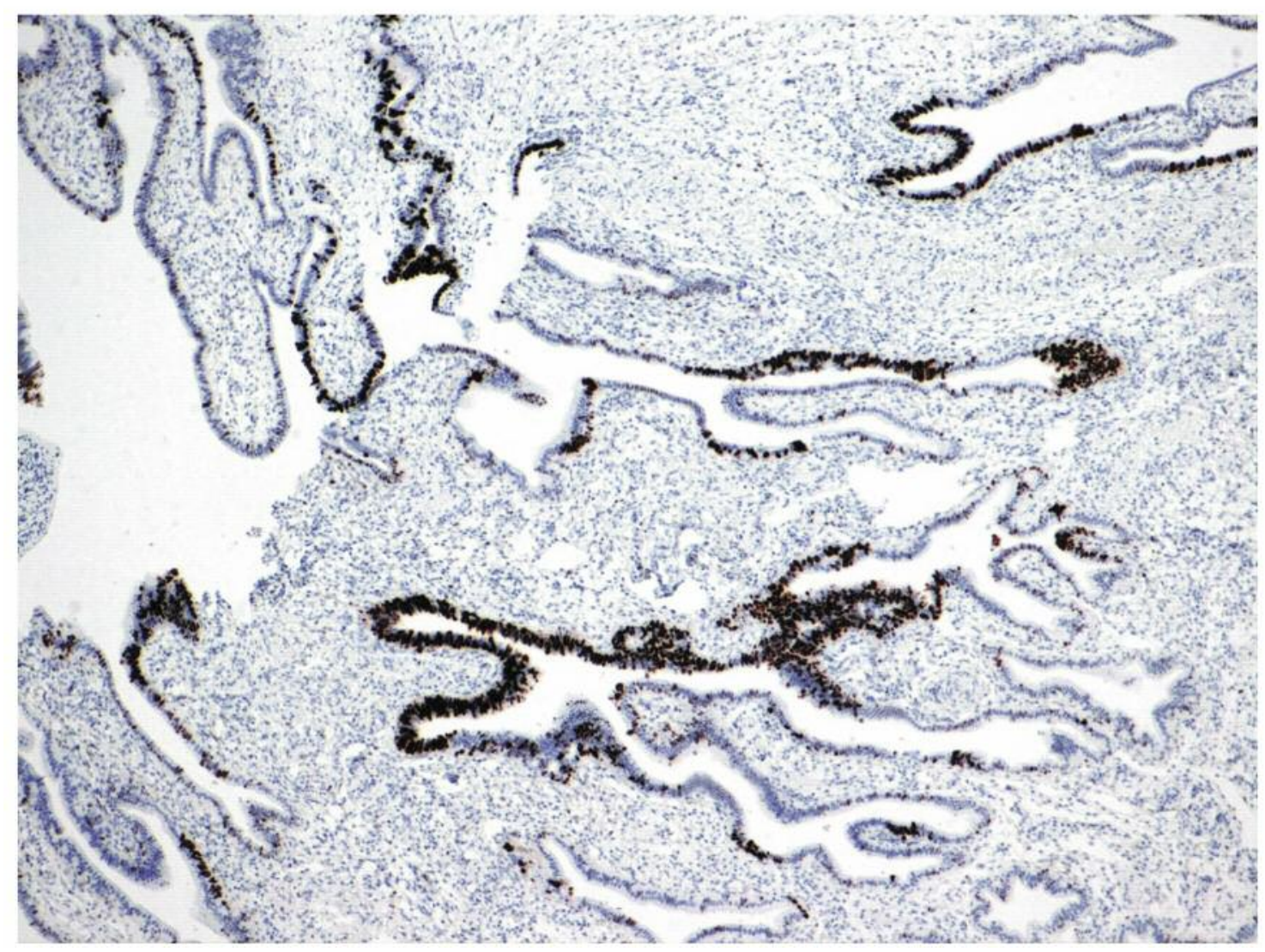

Figure 1. IHC p53 staining in a tubal specimen in a patient with Li-Fraumeni syndrome.

\section{Patients and Methods}

Since 1998, clinical and genetic data of all patients at higher risk of ovarian and breast cancer have been collected and recorded in collaboration with clinical geneticists, gynecologic oncologists and breast oncologists. Following internal guidelines women at high-risk for tubo-ovarian cancer (TOC) are counseled to consider RRSO by the age of 35 (BRCA1) or 40 (BRCA2), or later as soon as childbearing is completed. This applies also to women who tested negative for $B R C A$ mutations (also defined as ' $B R C A$-negative highrisk women') or to women with unknown $B R C A$ status whose estimated lifetime risk of developing ovarian cancer is $>10 \%$. After undergoing RRSO, women continue their follow-up for breast cancer screening at the Institute. Gynecologic follow-up was standardized including CA-125 measurement, gynecologic examination and pelvic US every 6 months. Surgical specimens from prophylactic surgery of women carrying a BRCAl-2 mutation and BRCA negative/unknown high-risk women were prospectively collected between January 1998 and April 2016. Inclusion criteria for prophylactic treatment were: asymptomatic women with a negative gynecologic screening (pelvic examination, transvaginal ultrasound) within 3 months prior to RRSO. Exclusion criteria: symptomatic women, patients with a positive gynecologic screening or women with ovarian/tubal cancer prior to RRSO. All women, carrying a BRCA mutation, enrolled in this study, had a proven pathogenic mutation (splice site mutations, nonsense mutations, frameshifts or exon deletions). Patients carrying an unclassified variant (UV) were incorporated in the group 'negative tested women'. Patients whose genetic test was unavailable were included in the BRCA-unknown group.

RRSO is a minimally-invasive surgical procedure that includes laparoscopic removal of the adnexa, the collection of peritoneal washing cytology and endometrial biopsy (Pipelle). Additional minimally-invasive hysterectomy was performed if indicated (higher risk of uterine cancer, desire of the patients, etc.).

Staging for tubal intraepithelial carcinoma (STIC), when performed, consisted of laparoscopic hysterectomy, omentectomy, random peritoneal biopsies and peritoneal washing. A retroperitoneal staging was performed in case of invasive cancers.

The specific aims of the present study were to evaluate the incidence of tubal minor epithelial atypia (STIL), STIC, and occult invasive cancer in patients undergoing RRSO.

Histopathology. From 2009, a strict surgico-pathological protocol (2006 Brigham and Women's protocol for sectioning and extensively examining the fimbrial end (SEE-FIM)) was applied consisting of transverse section at 2-3 mm intervals of both tubes and ovaries (17). A haematoxylin and eosin (H\&E) slide was prepared from ovaries and fallopian tubes specimens, for histology 


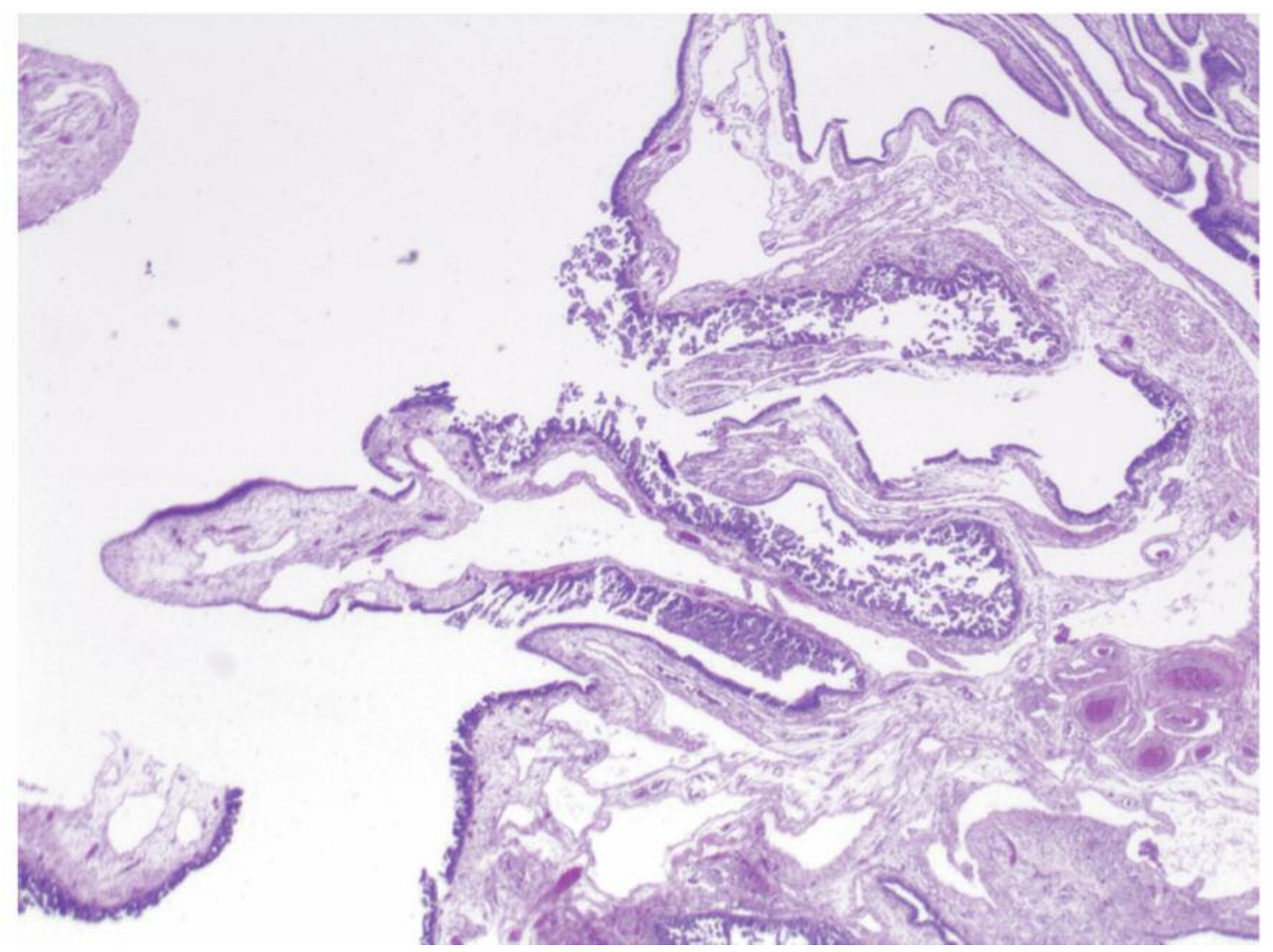

Figure 2. Serous tubal intraepithelial carcinoma (STIC).

and additional immunohistochemical p53 staining that can occur in both normal and neoplastic epithelium whereas immunostaining for MIB-1 (Ki67) is helpful to detect proliferative cells. Therefore, in selected cases, a MIB-1 (Ki67) staining was also performed.

Features for histological diagnosis of minor epithelial atypia (STIL) are: slightly enlarged, rounded nuclei with irregular cell membrane outlines, slightly enlarged nuclear/cytoplasmic ratio, nuclei with slight loss of polarity and inconspicuous nucleoli. Minor epithelial atypia is not visible at low power magnification. It comprises epithelial lesions that fulfill some but not all of the criteria for tubal intraepithelial carcinoma (TIC). Positive staining for p53 was not required for diagnosing STIL (Figure 1).

Tubal intraepithelial carcinoma is identifiable at low power magnification, displaying a row of dark and thickened epithelium. It is characterized by disorganized cellular crowding and nuclear stratification, and consists of secretory cells in absence of ciliated cells (Figure 2).

Histological features of tubal invasive carcinoma are identical to TIC, but with the addition of an invasive component (18).

Occult cancer is defined as a clinically unapparent invasive malignancy of the epithelium of the ovary or fallopian tube diagnosed at histopathological examination, according to the guidelines of the International Federation of Gynecology and Obstetrics (FIGO). Therefore, occult cancer refers to an invasive malignancy and not to an in situ component.
Table I. Mutational status of patients undergoing RRSO.

\begin{tabular}{lcc}
\hline Type of mutation & $\mathrm{N}^{\circ}$ of patients & $\%$ \\
\hline$B R C A 1$ & 157 & 38,2 \\
$B R C A 2$ & 119 & 29 \\
$B R C A 1-2$ & 14 & 3,4 \\
$B R C A$-negative & 60 & 14,6 \\
BRCA-unknown & 61 & 14,8 \\
Lynch syndrome & 6 & 1,5 \\
BRCA1 - Lynch syndrome & 2 & 0.5 \\
Li-Fraumeni & 1 & 0.2 \\
\hline
\end{tabular}

RRSO: Risk reducing salpingo-oophorectomy; BRCA: breast-related cancer antigens.

\section{Results}

From January 1998 to April 2016, 411 high-risk women underwent prophylactic surgery. Distribution by type of mutation is shown in Table I. Menopausal status, family history and age distribution are shown in Table II. A positive 
Table II. Demographics.

\begin{tabular}{|c|c|c|c|c|c|c|}
\hline & $\begin{array}{l}\text { BRCA1 } \\
(\mathrm{N}=157)\end{array}$ & $\begin{array}{l}\text { BRCA2 } \\
(\mathrm{N}=119)\end{array}$ & $\begin{array}{c}\text { BRCA1-2 } \\
(\mathrm{N}=14)\end{array}$ & $\begin{array}{l}\text { BRCA-negative } \\
\quad(\mathrm{N}=60)\end{array}$ & $\begin{array}{l}\text { BRCA-unknown } \\
\quad(\mathrm{N}=61)\end{array}$ & $\begin{array}{c}\text { Total } \\
(\mathrm{N}=411)\end{array}$ \\
\hline \multicolumn{7}{|l|}{ Menopausal status } \\
\hline Premenopausal & 96 & 40 & 7 & 15 & 26 & $184(44,8 \%)$ \\
\hline Postmenopausal & 61 & 79 & 7 & 44 & 35 & $226(55 \%)$ \\
\hline Not Available & & & & 1 & & $1(0,2 \%)$ \\
\hline \multicolumn{7}{|l|}{ Familiarity } \\
\hline Positive & $149(94,9 \%)$ & $110(92,4 \%)$ & $13(99,9 \%)$ & $56(93,3 \%)$ & $53(86,9 \%)$ & $381(92,7 \%)$ \\
\hline Negative & $8(5,1 \%)$ & $6(5 \%)$ & $1(0,1 \%)$ & $4(6,7 \%)$ & $8(13,1 \%)$ & $27(6,6 \%)$ \\
\hline Not Available & & $3(2,5 \%)$ & & & & $3(0,7 \%)$ \\
\hline \multicolumn{7}{|l|}{ Age } \\
\hline Median age at RRSO & $44(31-68)$ & $45(34-70)$ & $45,5(31-61)$ & $50(38-68)$ & $49(40-73)$ & $47(31-73)$ \\
\hline $\mathrm{BC}$ prior to RRSO & $116(73,9 \%)$ & $99(83,2 \%)$ & $11(78.6 \%)$ & $47(11,4 \%)$ & $36(8,76 \%)$ & $309(75,2 \%)$ \\
\hline Median age at first $\mathrm{BC}$ & $38(24-60)$ & $40(24-59)$ & $42(30-50)$ & $43(27-60)$ & $43,5(32-57)$ & $40(24-60)$ \\
\hline
\end{tabular}

N: Number; BRCA: breast related cancer antigens; RRSO: risk reducing salpingo-oophorectomy; BC: breast cancer.

Table III. Findings at RRSO.

\begin{tabular}{lcccccc}
\hline & BRCA1 & BRCA2 & BRCA1-2 & BRCA-negative & BRCA-unknown & Total \\
\hline Occult invasive cancers & $2(1.3 \%)$ & $1(0.8 \%)$ & - & $3(5 \%)(1.7 \%$ TOC) & $2(3.3 \%)(1.6 \%$ TOC) & $8(1.9 \%)(1 \%$ TOC) \\
Tubal CA & 1 & - & - & - & 1 & 1 \\
Ovarian CA & 1 & - & - & 1 & - & 2 \\
Metastatic BC & - & 1 & - & 1 & 1 & 2 \\
Endometrial endometrioid CA & - & - & - & - & - & 7 \\
STIC & $7(4.5 \%)$ & - & - & $5(8.3 \%)$ & $3(4.9 \%)$ & $16(3.9 \%)$ \\
STIL & $4(2.5 \%)$ & $4(3.4 \%)$ & - & & $1.7 \%)$ \\
\hline
\end{tabular}

RRSO: Risk-reducing salpingo-oophorectomy; BRCA: breast related cancer antigens; TOC: Tubo-Ovarian cancer; CA: cancer; BC: breast cancer; STIC: Serous tubal intraepithelial Cancer; STIL: serous tubal intraepithelial lesion.

family history was observed in 381 women, it was not available in 3 cases (having a BRCA2 mutation). A total of 29 women had a negative family history for cancer: 8 carrying a BRCA1 mutation, 6 with $B R C A 2$ mutations, 1 BRCA1-2, 4 $B R C A$-negative and $8 B R C A$ unknown (Table II).

Median age at RRSO was 47.0. A total of 309 (75.2\%) women had previously been diagnosed with breast cancer (BC). Median age at first BC was 40: 38 for BRCA1, 40 for $B R C A 2,43$ and 43.5 respectively for $B R C A$-negative and $B R C A$ unknown, 42 for BRCA1-2 (Table II). RRSO was performed in all patients. Concurrent hysterectomy was performed in 93 women $(22.6 \%)$ : 84 by minimally-invasive approaches (54 1ps and 30 robot-assisted laparoscopy) whereas 9 underwent laparotomy. Peritoneal washing was not available in two cases (one $B R C A$ negative and one $B R C A$ unknown), five specimens were inadequate. Atypical cells were detected in one $B R C A 2$ and in one $B R C A$-negative woman whose histology was negative. Malignant cells were retrieved in a $B R C A$ negative patient who had invasive OC. Fifteen $(3.7 \%$ ) occult carcinomas were diagnosed (Table III). These included 4 tubo-ovarian cancers and 2 endometrial endometrioid cancers (detected by Pipelle biopsy during RRSO), 2 BC metastatic to the adnexa, 7 STICs. Median age of occult carcinomas patients at RRSO was 54 (range=37-70). Sixteen patients were diagnosed with STIL (3.9\%) (Table III), with a mean follow-up of 3 years (range $=0-15$ years) none of them developed peritoneal cancer. All 7 STICs occurred among women carrying a BRCAl mutation, all but one with a positive family history for TOC. Median age at RRSO was 54 years (range $=43-67$ years). One was premenopausal, six postmenopausal. Six women had a positive personal history of BC. Preoperative CA125 was negative for all of them. Peritoneal washing was negative. Four patients underwent a restaging procedure, that was negative, while the other 3 were followed closely; none of them received adjuvant chemotherapy and with a median follow-up of 30 months 
Table IV. Tubo-ovarian invasive cancers at RRSO.

\begin{tabular}{|c|c|c|c|c|c|c|c|c|c|c|c|c|c|}
\hline Patient & $\begin{array}{l}\text { Age at } \\
\text { RRSO }\end{array}$ & $\begin{array}{l}\text { Mutational } \\
\text { status }\end{array}$ & $\begin{array}{c}\mathrm{BC} \\
\text { history }\end{array}$ & $\begin{array}{c}\text { Preop } \\
\text { CA125 }\end{array}$ & $\begin{array}{c}\text { US } \\
5 \text { stage }\end{array}$ & Pathology & Cytology & Staging & FIGO & CHT R & Recurrence & Status I & DFS OS \\
\hline 1 & 37 & $B R C A 1$ & $\begin{array}{l}\text { Negative } \\
\text { (at } 42 \\
\text { diagnosis } \\
\text { of triple } \\
\text { negative } \\
\text { BC) }\end{array}$ & 36 & Negative & $\begin{array}{c}0.4 \mathrm{~cm} \\
\text { HGSOC } \\
\text { OSE. FT: } \\
\text { negative }\end{array}$ & Negative & $\begin{array}{l}\text { Robot-assisted } \\
\text { hysterectomy, } \\
\text { omentectomy, } \\
\text { peritoneal } \\
\text { biopsies, } \\
\text { pelvic and } \\
\text { paraortic } \\
\text { lymphade- } \\
\text { nectomy }\end{array}$ & IC & $\begin{array}{l}6 \text { cycles } \\
\text { CBDCA }\end{array}$ & - & NED & 71 \\
\hline 2 & 59 & BRCA1 A & $\begin{array}{c}\text { At } 37 \text { triple } \\
\text { negative } \\
\text { BC }\end{array}$ & 8 & Negative & $\begin{array}{c}\text { right FT: } \\
\text { HGSTC. } \\
\text { Left FT: } \\
\text { STIC }\end{array}$ & $\begin{array}{r}\text { Negative } \\
\mathrm{p}\end{array}$ & $\begin{array}{l}\text { Robot-assisted } \\
\text { hysterectomy, } \\
\text { omentectomy, } \\
\text { peritoneal biopsies, } \\
\text { pelvic and } \\
\text { paraortic lympha- } \\
\text { denectomy }\end{array}$ & IA & $\begin{array}{l}6 \text { cycles } \\
\text { CBDCA }\end{array}$ & - & NED & 81 \\
\hline 3 & 62 & $\begin{array}{c}B R C A- \\
\text { negative, } \\
\text { positive FH } \\
B R C A 2 \\
\text { daughter }\end{array}$ & $\begin{array}{l}\text { Luminal } \\
\text { B BC } \\
\text { at } 60\end{array}$ & 51 & Negative & $\begin{array}{c}\text { HGSOC. } \\
\text { FT: } \\
\text { negative }\end{array}$ & Positive & $\begin{array}{l}\text { Laparoscopic } \\
\text { hysterectomy, } \\
\text { omentectomy, } \\
\text { peritoneal } \\
\text { biopsies }\end{array}$ & IIIC & $\begin{array}{c}6 \text { cycles } \\
\text { CBDCA+ } \\
\text { PTX }\end{array}$ & $\begin{array}{c}\mathrm{r} \\
\text { to }\end{array}$ & $\begin{array}{c}\text { AWD } \\
\text { (BC } \\
\text { metastatic } \\
\text { o the bone) }\end{array}$ & ) \\
\hline 4 & 67 & $\begin{array}{c}B R C A- \\
\text { unknown }\end{array}$ & - & 121 & Salpingitis & $\begin{array}{l}\text { HGSTC } \\
\text { metastatic to } \\
\text { the greater } \\
\text { omentum } \\
\text { and pelvic } \\
\text { and aortic } \\
\text { nodes }\end{array}$ & $\begin{array}{r}\text { Negative } \\
\\
1\end{array}$ & $\begin{array}{l}\text { Conversion } \\
\text { to laparotomy: } \\
\text { omentectomy } \\
\text { and pelvic } \\
\text { and paraortic } \\
\text { lymphadenectomy } \\
\text { (previous benign } \\
\text { hysterectomy) }\end{array}$ & $\begin{array}{c}\text { IIIC } \\
\text { (node } \\
\text { positive) }\end{array}$ & $\begin{array}{c}6 \text { cycles } \\
\text { CBDCA+ } \\
\text { PTX+ } \\
\text { BEVACI } \\
\text { ZUMAB } \\
\text { (furthered } \\
\text { as } \\
\text { maintenance } \\
\text { until 22 } \\
\text { cycles) }\end{array}$ & e & NED & 27 \\
\hline
\end{tabular}

RRSO: Risk-reducing salpingo-oophorectomy; BC: breast cancer; CA125: carbohydrate antigen 125; US: ultrasound findings; FIGO: International Federation of Gynecology and Obstetrics; CHT: chemotherapy; DFS: disease free survival; OS: overall survival; BRCA: breast related cancer antigens; STIC: serous tubal intraepithelial cancer; HGSOC: high grade serous ovarian cancer; OSE: ovarian surface epithelium; FT: fallopian tube; CBDCA: carboplatin; PTX: paclitaxel; HGSTC: high-grade serous tubal carcinoma; FH: familial history; NED: no evident disease; AWD: alive with disease.

(range=9-84 months) none of them developed peritoneal cancer. As shown in Table III invasive cancers were detected in eight patients. Median age at RRSO was 52.5 years (range $=37-70$ years). The 2 endometrial endometrioid cancers were diagnosed in the $B R C A$-negative/unknown group, with a median age at diagnosis of 60 . Details about FIGO stage, management and disease status of the 4 patients diagnosed with TOC are summarized in Table IV. Their median age at RRSO was 60.5 years (range $=37-67$ years). At a median FUP of 49 months (range $=11-81$ months) 3 patients are NED, whereas 1 is alive with $\mathrm{BC}$ metastatic to the bone. One $B R C A 2$ woman with negative pathology at RRSO (performed at 51 years of age) developed PPC STAGE FIGUREO IIIC at 15 months diagnosed by a raise in CA125. She received one line chemotherapy with CBDCA and PTX and she is presently NED at 46 months.

\section{Discussion}

Our study, based on one of the largest single-center series of tested subjects to date, showed a low prevalence of occult invasive cancer (1.9\%) and STIC (1.7\%) in high-risk women. Among those with invasive cancer two women had elevated preoperative CA125 (51 and $121 \mathrm{U} / \mathrm{ml}$ respectively) and therefore they should not have met the criteria for the definition of "true occult" cancer but nevertheless they were referred to us seeking prophylactic surgery. Both cases displayed extra-adnexal spread. 
Excluding those cases of EC and BC the rate of occult TOC in the entire study population drops to $1 \%$ that might be even a more realistic percentage, as it properly pictures the risk of occult cancers in this group of higher risk patients. The main strengths of our study are: the inclusion of consecutive and uniform series of asymptomatic, screennegative high-risk women, the large sample-size, and the long duration of follow-up. Moreover, added values are the independent histopathological review by two expert gynecologic pathologists, and the clear separation between $B R C A$-positive, BRCA-negative and BRCA-unknown cases, since most studies report on proven $B R C A$ carriers only. Furthermore, the fact that endometrial biopsy and peritoneal washing were routinely performed makes our results unique compared to those available in the literature. Moreover, this is the first report on the impact of RRSO on HBOC in Italy, accomplished in a leading nationwide cancer center.

Potential weaknesses may be the single-center nature of the study and the fact that the ethnicity of the population enrolled is mostly Caucasian white of southern European origin.

In light of upcoming new evidences of a more complex picture in the genetic risk of cancer and of the recently acquired knowledge that more genes are involved, even in the same pathway, our data might be useful as a basic background for future research and further understanding in the field of genetic cancer prevention (19).

We found a prevalence of occult cancer at RRSO of 5.7\% in BRCA-carriers. Conversely, the prevalence in the BRCAnegative/unknown was $4.1 \%$, corrected to $2.5 \%$ when the 2 uterine endometrial endometrioid cancers, detected in this subgroup, were excluded.

In the literature, the prevalence of occult cancer in $B R C A$ carriers and high-risk women varies considerably, from 2-3\% in large, mainly multicenter series to $7-12 \%$ in smaller, mostly single-center series. The lower prevalence of occult cancer in our series may be explained by the rigorous patient selection, the younger age at RRSO, the homogeneity and the significant size of the sample.

The detection of a true occult invasive cancer in a woman carrying a BRCAl mutationat the age of 37 is in agreement with data from the literature that underline the importance of anticipating a prophylactic surgical procedure in this subgroup of patient. This patient had no proven tubal lesion, despite performing multiple sections of the specimens and pathology revision. Although the fallopian tube is suggested to be the primary origin of tumorigenesis in $B R C A$-carriers, the ovary seems to be the favorite site for tumor growth beyond the microscopic stage (20-26).

Opportunistic salpingectomy, at the time of other benign gynecologic surgery as a primary preventive strategy, has been recommended for low risk women, as some studies have shown a risk reduction of ovarian cancer rate in women after bilateral prophylactic salpingectomy $(27,28)$.
Therefore, bilateral salpingectomy has been recently recommended as a temporary risk-reducing surgical procedure for $B R C A$-carriers as well, in order to avoid the menopausal symptoms deriving from oophorectomy. Many Authors $(29,30)$ seem to favor prophylactic salpingectomy around the age of 40 delaying oophorectomy at the age of 45 . The need of gathering more data, better if within a clinical trial, and the results of our current study would suggest a careful implementation into clinical practice of such a conservative approach.

In the present study, we describe a subgroup of women that has not yet been described to our knowledge in the available literature to date, it includes 14 women (3.4\%) who had a germinal pathogenic mutation in both BRCA 1 and 2 genes, whose clinical significance is still unclear. Two patients had a positive family history of cancers in the HBOC spectrum in both paternal and maternal line. Eleven out of fourteen $(78.6 \%)$ women had a previous history of BC: seven were triple negative, three luminal $\mathrm{B}$ and one luminal Her-2 tumors. Age at BC onset ranged from 30 to 50 years. Specimens collected at RRSO including peritoneal washing and endometrial biopsy were all negative.

All STICs were detected among BRCAl-carriers, with a prevalence of $4.5 \%$, which makes $1.7 \%$ of our entire higher risk population. In the literature STIC has been reported in $1-12 \%$ of the prophylactically removed ovaries and fallopian tubes in $B R C A$-carriers, mostly in the fimbrial end of the tube $(7,9-17)$. If we consider all $B R C A$-carriers in our population, percentage would be $2.4 \%$.

Invasive cancer and evidence of distant metastasis were not noted at the time of STIC surgical staging. It is still unclear how to properly manage these cases. In our study, peritoneal washing performed at the time of RRSO was negative, 4 patients were restaged whereas 3 were not. None of them received adjuvant treatment and with a median follow-up of 30 months (9-84), oncologic outcomes were equal. Therefore, even though the number is small, it seems that clinical follow-up without staging surgery or adjuvant treatment may be a reasonable option for this subgroup of patients (31).

The chance of developing peritoneal cancer after RRSO is been reported to be up to $4.3 \%$ in selected studies. In our series so far none of those patients who were diagnosed with STIC developed a peritoneal cancer. It is interesting to notice that a PPC was detected after 15 months in a patient with completely negative pathology findings at the time of RRSO. This finding highlights the importance of adopting a standardized and strict follow-up (32).

Sixteen atypical hyperplastic lesions (3.9\%) were detected, eight of them among BRCA-carriers (2.8\%), and none developed cancer. However, the clinical significance of atypical hyperplasia with cytological anomalies is still unclear; though, interestingly, the highest rate of STIL (8.3\%) was detected among BRCA-negative women. 
Our study, covering an 18-year period, shows a substantial low risk of diagnosing occult cancer among a high-risk population of women undergoing RRSO. Such a low detection rate might be due to the strict criteria for patients' selection, which include younger age at RRSO (particularly in women carrying a BRCA mutation) and a negative screening prior to surgery.

In conclusion, our data support the indication for RRSO in selected high-risk patients. A thorough follow-up is mandatory and we also believe that an endometrial biopsy should be routinely obtained as it raises the chances of detecting occult endometrial cancers that may be otherwise missed.

\section{References}

1 Ferlay J, Soerjomataram I, Ervik M, Dikshit R, Eser S, Mathers C, Rebelo M, Parkin DM, Forman D and Bray F: GLOBOCAN 2012 v1.0, Cancer Incidence and Mortality Worldwide: IARC CancerBase No. 11 [Internet]. Lyon, France: International Agency for Research on Cancer, 2013. Available from: http://globocan.iarc.fr, accessed on 25/02/2015.

2 Antoniou A, Pharoah PD, Narod S, Risch HA, Eyfjord JE, Hopper JL, Loman N, Olsson H, Johannsson O, Borg A, Pasini B, Radice P, Manoukian S, Eccles DM, Tang N, Olah E, AntonCulver H, Warner E, Lubinski J, Gronwald J, Gorski B, Tulinius $H$, Thorlacius S, Eerola H, Nevanlinna H, Syrjäkoski $K$, Kallioniemi OP, Thompson D, Evans C, Peto J, Lalloo F, Evans DG and Easton DF: Average risks of breast and ovarian cancer associated with BRCA1 or BRCA2 mutations detected in case series unselected for family history: a combined analysis of 22 studies. Am J Hum Genet 72(5): 1117-1130, 2003.

3 Rebbeck TR, Lynch HT, Neuhausen SL, Narod SA, Van't Veer L, Garber JE, Evans G, Isaacs C, Daly MB, Matloff E, Olopade OI and Weber BL; Prevention and Observation of Surgical End Points Study Group: Prophylactic oophorectomy in carriers of BRCA1 or BRCA2 mutations. N Engl J Med 346: 1616-1622, 2002.

4 Domchek SM, Friebel TM, Neuhausen SL, Wagner T, Evans G, Isaacs C, Garber JE, Daly MB, Eeles R, Matloff E, Tomlinson GE, Van't Veer L, Lynch HT, Olopade OI, Weber BL and Rebbeck TR: Mortality after bilateral salpingo-oophorectomy in BRCA1 and BRCA2 mutation carriers: a prospective cohort study. Lancet Oncol 7(3): 223-229, 2006.

5 Casey MJ, Synder C, Bewtra C, Narod SA, Watson P and Lynch HT: Intra-abdominal carcinomatosis after prophylactic oophorectomy in women of hereditary breast ovarian cancer syndrome kindreds associated with BRCA1 and BRCA2 mutations. Gynecol Oncol 97(2): 457-467, 2005.

6 Domchek SM, Friebel TM, Garber JE, Isaacs C, Matloff E, Eeles R, Evans DG, Rubinstein W, Singer CF, Rubin S, Lynch HT, Daly MB, Weitzel J, Ganz PA, Pichert G, Olopade OI, Tomlinson G, Tung N, Blum JL, Couch F and Rebbeck TR: Occult ovarian cancers identified at risk-reducing salpingooophorectomy in a prospective cohort of BRCA1/2 mutation carriers. Breast Cancer Res Treat 124: 195-203, 2010.

7 Rabban JT, Barnes M, Chen LM, Powell CB, Crawford B and Zaloudek CJ: Ovarian pathology in risk-reducing salpingo- oophorectomies from women with BRCA mutations, emphasizing the differential diagnosis of occult primary and metastatic carcinoma. Am J Surg Pathol 33: 1125-1136, 2009.

8 Hirst JE, Gard GB, McIllroy K, Nevell D and Field M: High rates of occult fallopian tube cancer diagnosed at prophylactic bilateral salpingo-oophorectomy. Int J Gynecol Cancer 19: 826829, 2009.

9 Powell CB, Kenley E, Chen LM, Crawford B, McLennan J, Zaloudek C, Komaromy M, Beattie $\mathrm{M}$ and Ziegler J: Riskreducing salpingo- oophorectomy in BRCA mutation carriers: role of serial sectioning in the detection of occult malignancy. $\mathrm{J}$ Clin Oncol 23: 127-132, 2005.

10 Hirst JE, Gard GB, McIllroy K, Nevell D and Field M: High rates of occult fallopian tube cancer diagnosed at prophylactic bilateral salpingo-oophorectomy. Int J Gynecol Cancer 19: 826829, 2009.

11 Powell CB, Chen LM, McLennan J, Crawford B, Zaloudek C, Rabban JT, Moore DH and Ziegler J: Risk-reducing salpingooophorectomy (RRSO) in BRCA mutation carriers: experience with a consecutive series of 111 patients using a standardized surgical-pathological protocol. Int J Gynecol Cancer 21: 846$851,2011$.

12 Manchanda R, Abdelraheim A, Johnson M, Rosenthal AN, Benjamin E, Brunell C, Burnell M, Side L, Gessler S, Saridogan E, Oram D, Jacobs I and Menon U: Outcome of risk-reducing salpingo-oophorectomy in BRCA carriers and women of unknown mutation status. BJOG 118: 814-824, 2011.

13 Rhiem K, Foth D, Wappenschmidt B, Gevensleben H, Büttner $\mathrm{R}$, Ulrich $\mathrm{U}$ and Schmutzler RK: Risk-reducing salpingooophorectomy in BRCA1 and BRCA2 mutation carriers. Arch Gynecol Obstet 283: 623-627, 2011.

14 Meeuwissen PA, Seynaeve C, Brekelmans CT, Meijers-Heijboer HJ, Klijn JG and Burger CW: Outcome of surveillance and prophylactic salpingo-oophorectomy in asymptomatic women at high risk for ovarian cancer. Gynecol Oncol 97: 476-482, 2005.

15 Colgan TJ, Murphy J, Cole DE, Narod S and Rosen B: Occult carcinoma in prophylactic oophorectomy specimens: prevalence and association with BRCA germline mutation status. Am J Surg Pathol 25: 1283-1289, 2001.

16 Mingels MJ, Roelofsen T, van der Laak JA, de Hullu JA, van Ham MA, Massuger LF, Bulten J and Bol M: Tubal epithelial lesions in salpingo-oophorectomy specimens of BRCA-mutation carriers and controls. Gynecol Oncol 127(1): 88-93, 2012.

17 Medeiros F, Muto MG, Lee Y, Elvin JA, Callahan MJ, Feltmate C, Garber JE, Cramer DW and Crum CP: The tubal fimbria is a preferred site for early adenocarcinoma in women with familial ovarian cancer syndrome. Am J Surg Pathol 30: 230236, 2006.

18 Lynch HT, Casey MJ, Shaw TG and Lynch JF: Hereditary factors in gynecologic cancer. Oncologist 3: 319-338, 1998.

19 Crum CP, Drapkin R, Kindelberger D, Medeiros F, Miron A and Lee Y: Lessons from BRCA: the tubal fimbria emerges as an origin for pelvic serous cancer. Clin Med Res 5: 35-44, 2007.

20 Kim J, Coffey DM, Creighton CJ, Yu Z, Hawkins SM and Matzuk MM: High-grade serous ovarian cancer arises from fallopian tube in a mouse model. Proc Natl Acad Sci USA 109: 3921-3926, 2012.

21 Roh MH, Kindelberger D and Crum CP: Serous tubal intraepithelial carcinoma and the dominant ovarian mass: clues to serous tumor origin? Am J Surg Pathol 33: 376-383, 2009. 
22 Yates MS, Meyer LA, Deavers MT, Daniels MS, Keeler ER, Mok SC, Gershenson DM and Lu KH: Microscopic and earlystage ovarian cancers in BRCA1/2 mutation carriers: building a model for early BRCA-associated tumorigenesis. Cancer Prev Res (Phila) 4: 463-470, 2011.

23 Carcangiu ML, Peissel B, Pasini B, Spatti G, Radice P and Manoukian S: Incidental carcinomas in prophylactic specimens in BRCA1 and BRCA2 germ-line mutation carriers, with emphasis on fallopian tube lesions: report of 6 cases and review of the literature. Am J Surg Pathol 30: 1222-1230, 2006.

24 Kindelberger DW, Lee Y, Miron A, Hirsch MS, Feltmate C, Medeiros F, Callahan MJ, Garner EO, Gordon RW, Birch C, Berkowitz RS, Muto MG and Crum CP: Intraepithelial carcinoma of the fimbria and pelvic serous carcinoma: evidence for a causal relationship. Am J Surg Pathol 31: 161-169, 2007.

25 Collins IM, Domchek SM, Huntsman DG and Mitchell G: The tubal hypothesis of ovarian cancer: caution needed. Lancet Oncol 12: 1089-1091, 2011.

26 SGO Clinical Practice Statement. https://www.sgo.org/clinicalpractice/guidelines/sgo-clinical-practice-statement-salpingectomy-for-ovarian-cancer-prevention/(Accessed on January 27, 2016).

27 Committee on Gynecologic Practice. Committee opinion no. 620: Salpingectomy for ovarian cancer prevention. Obstet Gynecol 125: 279, 2015.

28 Kwon JS, Tinker A, Pansegrau G, McAlpine J, Housty M, McCullum M and Gilks CB: Prophylactic salpingectomy and delayed oophorectomy as an alternative for BRCA mutation carriers. Obstet Gynecol 121(1): 14-24, 2013.
29 Leblanc E, Narducci F, Farre I, Peyrat JP, Taieb S, Adenis C and Vennin P: Radical fimbriectomy: a reasonable temporary risk-reducing surgery for selected women with a germ line mutation of BRCA 1 or 2 genes? Rationale and preliminary development. Gynecol Oncol 121: 472-476, 2011.

30 Harmsen MG, IntHout J, Arts-de Jong M, Hoogerbrugge N, Massuger LF, Hermens RP and de Hullu JA: Salpingectomy With Delayed Oophorectomy in BRCA1/2 Mutation Carriers: Estimating Ovarian Cancer Risk. Obstet Gynecol 127(6): 10541063, 2016

31 Patrono MG, Iniesta MD, Malpica A, Lu KH, Fernandez RO, Salvo G and Ramirez PT: Clinical outcomes in patients with isolated serous tubal intraepithelial carcinoma (STIC): a comprehensive review. Gynecol Oncol 139(3): 568-572, 2015.

32 Finch A, Beiner M, Lubinski J, Lynch HT, Moller P, Rosen B, Murphy J, Ghadirian P, Friedman E, Foulkes WD, Kim-Sing C, Wagner T, Tung N, Couch F, Stoppa-Lyonnet D, Ainsworth P, Daly M, Pasini B, Gershoni-Baruch R, Eng C, Olopade OI, McLennan J, Karlan B, Weitzel J, Sun P and Narod SA; Hereditary Ovarian Cancer Clinical Study Group: Salpingo-oophorectomy and the risk of ovarian, fallopian tube, and peritoneal cancers in women with a BRCA1 or BRCA2 Mutation. JAMA 296: 185-192, 2006.

Received July 4, 2017

Revised July 24, 2017

Accepted August 2, 2017 